\title{
Prisons: Health Hazards, But Also Health OPPORTUNITIES
}

\author{
Caren Weilandt ${ }^{1}$, Doris Radun ${ }^{2}$
}

1. WIAD, Scientific Institute of the German Medical Association, Bonn, Germany

2. Robert Koch-Institut, Berlin, Germany

\begin{abstract}
"Prisons are among the most unhealthy places in our societies. In them, people are not only deprived of their freedom but they are also exposed to threats such as violence, addiction and infectious diseases, while at the same time their own capacity to manage these risks is severely constrained" [1].
\end{abstract}

Worldwide, there is a high prevalence of bloodborne diseases such as hepatitis B, hepatitis C, or HIV among prisoners. This is largely due to a high prevalence of injecting drug users (IDUs) among detainees who have been infected by sharing needles or other paraphernalia. Moreover, injecting drug use is often continued within prisons in unsanitary conditions, or prisoners begin injecting while in prison. Tattooing, unprotected sexual intercourse and crowded living conditions also boost risks for infection [2-7].

Some studies indicate that IDUs who continue injecting while in prison are much more likely to share injecting equipment than injectors in the community.

There is an obvious lack of systematic documentation and research on health issues in European prisons. However, there are some valuable starting points in gathering information which could support health planning and policy making.

The Health in Prison Project (HIPP) of the World Health Organization Regional Office for Europe (http://www.euro.who.int/ prisons) has recently launched a Prison Health Database, which has been developed in collaboration with the European Monitoring Centre for Drugs and Drug Addiction (EMCDDA) and the European Network on Drugs and Infectious Prevention in Prison (ENDIPP). The database includes a large number of relevant indicators on prison health. In connection to the database a tool for data presentation was developed (http://data.euro.who.int/hip/).

Countries are currently providing penal statistics on the epidemiology of HIV/AIDS, hepatitis B and C, TB, STIs, violence/ suicides, mental disorders and on specific interventions or preventive measures. Based on this information, it will soon be possible to develop indicators for "good" prison health and to use this database as an instrument for policy monitoring within European prison systems $[8,9]$.

Currently, several studies on the prevalence of bloodborne infections and related risk behaviours in prisons are being finalised in different European countries. They are based on the
WASH (Willing Anonymous Salivary HIV/hepatitis C surveillance) method, like the one presented by Danis and colleagues in this issue, and have been carried out under guidance of the EC funded ENDIPP Network (www.endipp.net) [10]. These studies comply with the technical term "second generation surveillance", as they merge information on prevalence with information on knowledge, attitudes, behaviour and practices of prisoners and prison staff [11]. Prison staff were included in the surveys, since they represent a key element in all stages of prevention and harm reduction.

Surveys have been carried out in Armenia and Belgium using saliva for bloodborne virus detection, in Poland and Estonia using full blood samples, and another survey is ongoing in Germany using dried blood spots [12]. Their outcomes will determine better tailored recommendations for the responsible ministries in order to improve prevention and care inside prisons.

The United Nations Office on Drugs and Crime has recently published another, more general, framework for effective national responses regarding HIV/AIDS prevention, care, treatment and support in prison settings [13]. This framework sets out principles and actions for management of prisons but also for treatment of prisoners. It provides a useful tool for countries to support the implementation of evidence based interventions. Its objectives include aspects of prevention, treatment, and support regarding HIV/AIDS among prisoners that equal the very same standards available to people in the community outside of prison.

HIPP is about to publish an international guide, "Promoting Health in Prisons: The Essentials", which will outline key points regarding health promotion in prisons in general, and will also touch issues related to other infectious diseases.

In this issue, C Danis and colleagues present results from a cross-sectional survey on viral hepatitis and HIV among prisoners in Northern Ireland. Although the survey revealed a comparatively low prevalence of bloodborne infections among prisoners, based on test results of oral fluid specimens, the authors warn, correctly, that this is not a reason for complacency. Again, a clear relationship between infection with hepatitis $\mathrm{B}$ or $\mathrm{C}$ and injecting drug use is shown, and the authors recommend that measures should be taken in order to minimise potential transmission of bloodborne infections in prison.

Studies in other countries indicated varying, but generally much 
higher prevalences of bloodborne infections among prisoners. However, common to all of them was a pronounced link between injecting drug use and incremental seroprevalence [3-6, 14-16].

It should be noted that good prison healthcare is good public health. In terms of potential for preventive measures, the prison setting provides a unique opportunity for prevention (in an otherwise hard to reach population), e.g. vaccination of risk groups against hepatitis $B$ infection $[17,18]$. It should be borne in mind that in the long run, prison based harm reduction strategies and vaccination programmes will have a marked impact also upon the communitybased burden of infectious diseases, as a considerable proportion of society is exposed to the prison system. Most of the prisoners are eventually released and rejoin society. Moreover, the majority of detainees spends only limited time periods in prison, and repeated imprisonment is common.

Another important aspect in preventing spread of infectious diseases in prisons is educating staff and prisoners alike: it is vital that modes of transmission of bloodborne viruses are known in order to guarantee adherence to disease prevention strategies and to successfully promote health in prisons in the broader sense. Moreover, counselling and testing of prisoners, offering vaccinations and treatment of drug addiction or infectious diseases are of utmost importance, as well as preventing and managing accidental occupational exposure among the prison staff [19].

Even though specific harm reduction programmes have shown to be cost-effective, measures are generally adopted hesitantly, if at all $[20,21]$.

"It is insufficiently recognized that much more can be done within our prison system to reduce the harm from drugs and to treat successfully a large number of prisoners who are addicted to drugs. The promotion of health in prison can make a major contribution to national strategies for tackling the problems of drugs (including alcohol) in society" [9].

Namely, there is a need for increased infection control and harm reduction measures in prisons. Researchers and health planners likewise need to recognise the pivotal role prisons play in the context of infectious disease epidemiology, and they need to meet the challenge in improving health for those behind bars.

\section{References}

1. Bollini P, editor. HIV in prisons: A reader with particular relevance to the Newly Independent States. World Health Organization (WHO) Regional Office for Europe; Copenhagen; 2001. Available from: http://www.euro.who. int/document/e77016.pdf

2. Gore SM et al: Prevalence of hepatitis $C$ in prisons: WASH-C surveillance linked to self-reported risk behaviours. Q Med 1999; 92:25-32.

3. Taylor $A$ et al: Prevalence of hepatitis $C$ virus infection among injecting drug users in Glasgow, 1990-1996: are current harm reduction strategies working? J Infect 2000; 40:176-83.

4. Long $\mathrm{J}$ et al: Prevalence of antibodies to hepatitis B, hepatitis $\mathrm{C}$, and HIV and risk factors in entrants to Irish prisons: a national cross-sectional survey. BMJ 2001; 323:1209-13.

5. Weild AR et al: Prevalence of HIV, hepatitis $B$, and hepatitis $C$ antibodies in prisoners in England and Wales: a national survey. Commun Dis Public Health 2000; 3:121-6.

6. Rotily $M$ et al: Surveillance of HIV infection and related risk behaviour in European prisons. A multicentre pilot study. Europ J Pub Health 2001; 11:243-50.

7. Centers for Disease Control and Prevention. HIV Transmission Among Male Inmates in a State Prison System - Georgia, 1992-2005. MMWR Weekly. 2006; 55(15): 421-426. (http://www.cdc.gov/mmwr/preview/mmwrhtml/mm5515a1. htm?s_cid=mm5515a1_e\%0d\%0a)

8. World Health Organization. Status Paper on Prisons, Drugs and Harm Reduction. Copenhagen: World Health Organization Regional Office for Europe; 2005 (http://www.euro.who.int/document/e85877.pdf)

9. WHO/Europe 2001: "Prisons, Drugs and Society: A consensus statement on Principles, Policies and Practices, Copenhagen, 2001" (http://www.euro.who. int/document/E81559.pdf)

10. Bird SM, Rotily M: Inside Methodologies: For Counting Blood-Borne Viruses and Injector-Inmates' Behavioural Risks - Results From European Prisons. Howard J Criminal Justice 2002; 41 (2): 123-136.

11. Zaba B et al: The role of behavioral data in HIV surveillance. AIDS. 2005 May;19 Suppl 2:39-52.

12. Weilandt $C$ et al: Anonymous survey on infectious diseases and related risk behaviour among Armenian prisoners and prison staff. Int J Prisoner Health, 2007; 3(1): 1-12.

13. United Nations Office on Drugs and Crime: A framework for an effective national response - HIV/AIDS prevention, care, treatment and support in prison settings (http://www.iprt.ie/international/1819)

14. Meyer MF et al: Prevalence of hepatitis $C$ in a German prison for young men in relation to country of birth. Epidemiol Infect 2006; Jul 7:1-7 [Epub ahead of print].

15. Stark $\mathrm{K}$ et al: History of syringe sharing in prison and risk of hepatitis $B$ virus, hepatitis $C$ virus, and human immunodeficiency virus infection among injecting drug users in Berlin. Int J Epidemiol 1997; 26:1359- 1366.

16. Dolan $\mathrm{K}$ et al: HIV in prison in low-income and middle-income countries. Lancet 2007; 7: 32-41.

17. Sutton AJ, Gay NJ, Edmunds WJ: Modelling the impact of prison vaccination on hepatitis $B$ transmission within the injecting drug user population of England and Wales. Vaccine. 2006;24(13):2377-86.

18. Hutchison SJ et al: Sudden rise in uptake of hepatitis B vaccination among injecting drug users associated with a universal vaccine programme in prisons. Vaccine 2004; 23: 210-4.

19. Testa AC et al: HIV transmission in part of the US prison system: implications for Europe. Eurosurveillance 2006;11 (5):060525.

20. Stark $\mathrm{K}$ et al: A syringe exchange programme in prison as prevention strategy against HIV infection and hepatitis B and C in Berlin, Germany. Epidemiol. Infect. 2006;134: 814-9.

21. Pisu $M$ et al: Cost-effectiveness of hepatitis $B$ vaccination of prison inmates. Vaccine 2002;21: 312-21).

Citation: Weilandt C, Radun D, . Prisons: health hazards, but also health opportunities. Euro Surveill 2007;12(1)[Epub ahead of print]. Available online: http://www. Euro Surveill 2007;12(1)[Epub ahead of prir
eurosurveillance.org/em/v12n01/1201-221.asp 